\title{
O RESGATE DE UMA EXPERIÊNCIA ESVAZIADA: EL RUIDO DE LAS COSAS AL CAER E A FICÇÃO SOBRE O NARCOTRÁFICO
}

THE RECOVERY OF AN EMPTIED EXPERIENCE: EL RUIDO DE LAS COSAS AL CAER AND THE FICTION ABOUT DRUG TRAFFICKING

\section{Diogo de Hollanda Cavalcanti}

Universidade Federal do Rio de Janeiro

Rio de Janeiro, Brasil

\begin{abstract}
Resumo
Partindo de uma abordagem ampla que contextualiza a transformação da violência num tema dominante da cultura e dos meios de comunicação de massa latino-americanos, este artigo faz uma análise do romance El ruido de las cosas al caer (2011), do escritor colombiano Juan Gabriel Vásquez. Ao evocar o sentimento de medo da geração que cresceu em Bogotá nos anos do narcoterrorismo, a obra busca restituir uma experiência que corre o risco de ser esvaziada pela proliferação de discursos sensacionalistas e sem compromisso com a memória.
\end{abstract}

Palavras-chave: Literatura latino-americana; violência na literatura; literatura e política; literatura e jornalismo; literatura colombiana; Juan Gabriel Vásquez.

\section{Resumen}

Partiendo de un panorama amplio que contextualiza la transformación de la violencia en un tema dominante de la cultura y de los medios latinoamericanos, este artículo hace un análisis de la novela El ruido de las cosas al caer (2011), del escritor colombiano Juan Gabriel Vásquez. Al evocar el sentimiento de miedo de la generación que creció en Bogotá durante los años del narcoterrorismo, la obra busca restituir una experiencia que corre el riesgo de vaciarse con la proliferación de discursos sensacionalistas y sin compromiso con la memoria.

Palabras clave: Literatura latinoamericana; violencia en la literatura; literatura y política; literatura y periodismo; literatura colombiana; Juan Gabriel Vásquez.

\section{Abstract}

Beginning with a wide overview that contextualizes the transformation of violence in a major subject in Latin American culture and mass media, this paper makes an analysis of the novel El ruido de las cosas al caer (2011), by Colombian writer Juan Gabriel Vásquez. Evoking the fear felt by the generation who grew up in Bogotá during the narco-terrorism years, the book seeks to restore an experience that could be lost with the proliferation of sensationalist discourses without commitment to memory.

Keyword: Latin American literature; violence in literature; literature and politics; literature and journalism; Colombian literature; Juan Gabriel Vásquez. 
A violência é um tema tão antigo quanto a literatura e, particularmente na Colômbia, sua longa e acentuada presença chega a sugerir uma ideia de perenidade, como se as narrativas ambientadas no país tivessem sempre abordado, em maior ou menor medida, os conflitos que atravessam sua história. Embora não seja exatamente correta - já que em alguns momentos a violência sequer esteve entre os principais assuntos dos escritores (GUTIÉRREZ MAVESOY, 2014: 29) -, esta impressão de permanência, ou seja, de que se trata de um tópico irremovível da literatura colombiana, tornou-se inevitável nas últimas décadas, quando um aluviáo de obras sobre o tema deu a ele centralidade inconteste. Neste período, mais do que um fenômeno local, o interesse pela violência espraiou-se por toda a literatura latino-americana, assim como ocorreu com o cinema, a televisão e outros meios de comunicação de massa.

Não por acaso, esta inflexão começou nos anos 1980 - conhecidos como "a década perdida" para a América Latina - e se consolidou no decênio seguinte, quando se multiplicaram na regiāo os projetos neoliberais, apregoando um Estado mínimo e o poder ilimitado ao mercado. Em um artigo sobre a explosão do narcotráfico no México, Carlos Monsiváis (2004) inseriu o problema em um mal maior, denominado por ele "a criminalidade neoliberal”, isto é, a exclusão deliberada de milhóes de pessoas por políticas que, sob a fachada da meritocracia e do aumento da competitividade, convertem seres humanos em objetos descartáveis, ignorando direitos sociais e desconsiderando os passivos históricos do subcontinente. Se a combinação de crescimento pífio com inflação exorbitante - a chamada "estagflação", no jargão econômico - já havia resultado no aumento alarmante dos níveis de pobreza na década de 1980, o cenário nos anos 1990 não melhorou, pois, apesar do controle de preços obtido em alguns países, os programas de privatização e ajuste fiscal elevaram o desemprego e provocaram uma queda drástica dos investimentos públicos.

Esta conjuntura adversa, longe de explicar de todo, certamente contribuiu para a escalada da violência na América Latina que assistiu, no mesmo período, ao crescimento exponencial do tráfico de drogas, indissociável do quadro econômico e da ideologia de prazer, hiperatividade e consumo alimentada pelo neoliberalismo. Até entáo fenômeno modesto, praticado sem alarde nos grandes centros, o narcotráfico se agigantou nos anos 1980, alterando a paisagem urbana, introduzindo novos valores e constituindo-se como força desestabilizadora, capaz de desafiar o Estado sempre que necessário. Embates armados entre facções rivais, ou entre traficantes e forças policiais, passaram a ser comuns nas grandes cidades, modificando a rotina da população e levando ao paroxismo sentimentos como o medo, a imprevisibilidade e a sensaçáo de 
descontrole. Diana Klinger (2013: 134-135) nota, com acerto, que o recrudescimento da violência, somado a outros inumeráveis problemas, evidencia o fracasso do "sonho de ordem" simbolizado outrora pelas cidades, conforme analisou Ángel Rama (1984). Se antes se propunham a ser o bastiāo da civilização - contrapondo-se à suposta barbárie que imperava no campo -, as cidades se tornaram palco por excelência de manifestaçóes bárbaras, distanciando-se cada vez mais dos espaços vibrantes, embora já conturbados, celebrados pelos modernistas. Como comparou Monsiváis, "na megalópole do fim do século XX, um dos substitutos do flanneur é a Vítima Potencial, que faz da desconfiança seu instrumento de conhecimento e do receio sua bússola" (MONSIVÁIS, 1999: 40, tradução nossa).

Essas questôes permearam de maneira notável a literatura e outras expressões culturais a partir da década de 1980. Em alguns países, as ficçôes sobre a violência chegaram a engendrar subgêneros narrativos, como a chamada novela del narco, no México, e a Literatura de sicarios, na Colômbia, também conhecida como novela del sicariato ou sicaresca. Sem propor uma taxonomia rígida para esses rótulos - utilizados, aliás, com critérios maleáveis por críticos e pesquisadores -, podemos apontar alguns traços recorrentes. Enquanto a denominação mexicana costuma abranger narrativas que giram em torno da figura do chefão do tráfico - suas excentricidades, sua frieza, sua intimidade com o poder público -, a modalidade colombiana enfoca um personagem anteriormente desconhecido que se incorporou tragicamente à vida urbana. Trata-se do matador a soldo, o atirador de boa mira que, na garupa de uma moto, circula pelas ruas abatendo políticos, juízes, jornalistas e outros alvos célebres e anônimos - geralmente designados pelo tráfico. Tamanho o trauma deixado pelos sicários - quase sempre jovens pobres com brutal consciência de sua brevidade - que várias cidades colombianas chegaram a proibir o tráfego de motocicletas com passageiros no banco traseiro.

Embora haja registros anteriores - Gutiérrez Mavesoy (2014: 32), por exemplo, cita El sicario, de Mario Bahamón Dussán (1988), entre as obras precursoras -, a sicaresca ganhou projeção com os romances Virgen de los sicarios, de Fernando Vallejo (1994), e Rosario Tijeras, de Jorge Franco (1999), identificados muitas vezes como emblemas do subgênero, apesar dos críticos que refutam um pertencimento estrito. Ambientados na Medellín tempestuosa dos anos 1990 - que se consagrou como a "capital mundial do narcotráfico", graças ao cartel chefiado por Pablo Escobar-, os dois romances mostram uma situaçáo desgovernada de violência, narrada por personagens que se apaixonam por matadores e, engolfados em um mundo que desconhecem, revelam-se incapazes (ou francamente desinteressados, como o narrador de Vallejo) de decifrar a origem do caos. Com um tom sarcástico e uma temporalidade 
difusa que conferem aos assassinatos da trama um caráter vertiginoso e desprovido de sentido, o romance de Vallejo expóe na própria enunciação um dos desafios de abordar a violência na Colômbia: elaborar de forma inteligível uma experiência marcada pela incompreensão, pela inapreensibilidade de um cenário em que as tragédias ocorrem diariamente sem que se vislumbrem soluçôes ou se conheçam ao certo as forças que as movem (WALDE, 2000; 2001). Esta quase incomunicabilidade é acrescida de outro obstáculo: a profusão de discursos que, emanados de todas as partes, sáo produzidos sobre a violência. Como diz Erna von der Walde:

Os jornais, a televisão, a rádio, as revistas, os estudos acadêmicos, os testemunhos, os relatórios das ONGs invadem diariamente a vida dos colombianos com dados, versôes, estatísticas, interpretaçóes sobre uma realidade que não se deixa narrar e na qual impera, sobretudo, o medo. (WALDE, 2001: 31, tradução nossa)

Diante disso, a pesquisadora se pergunta:

Qual é o lugar da literatura neste espaço de superabundância de mensagens, justamente quando a letra está sendo descentrada de seu lugar ordenador da cultura e passou a ser uma manifestação cultural marginal em um país que não conseguiu saldar sua dívida educacional? (WALDE, 2001: 34, tradução nossa)

Embora não seja explicitamente formulada, esta é uma das questôes fundamentais de El ruido de las cosas al caer. Ao evocar o sentimento de medo da geraçáo que cresceu em Bogotá entre os anos 1980 e 1990 - da qual ele mesmo faz parte -, Vásquez busca restituir uma experiência que corre o risco de ser esvaziada pela proliferação de discursos sensacionalistas e sem compromissos com a memória. Não é fortuito que o relato do personagem narrador, Antonio Yammara, nasça em meio ao circo montado pela imprensa em torno da fuga dos hipopótamos de Pablo Escobar. Tampouco é casual que Maya Laverde comece sua investigação depois de saber da morte do pai em uma matéria mórbida no jornal que mais deplorava. Nas explicaçóes que perseguem e nas motivaçóes que os movem, os dois personagens vão na direção contrária da crônica frívola e espetacular dos meios de comunicaçâo de massa.

A passividade que, segundo Ricardo Piglia (2012), caracteriza os consumidores de notícia aparece em diferentes momentos do romance de Vásquez. Os bogotanos, diz Yammara, haviam se acostumado à violência "en parte porque sus imágenes llegaban con portentosa regularidad de los noticieros y los periódicos" (VÁSQUEZ, 2011: 18). Em frente à televisão da sinuca, os jogadores se inteiram do assassinato de um político, mas ninguém pergunta por que ou quem teria cometido o crime, pois "esas preguntas habían dejado de tener sentido en mi ciudad” (VÁSQUEZ, 2011: 18). A resignação "era una suerte de idiosincrasia nacional, el legado que nos dejaba nuestro tiempo" 
(VÁSQUEZ, 2011: 19), conta o personagem narrador. "El crimen de Laverde", diz, "era uno más, y resultaba casi arrogante o pretencioso creer que a nosotros nos correspondería el lujo de una respuesta" (VÁSQUEZ, 2011: 54).

Numa sociedade como essa, tudo, mais do que nunca, parece fadado ao esquecimento. Na noite em que Ricardo Laverde morre, outros dezesseis homicídios ocorrem em Bogotá, mas apenas dois ficam na memória do protagonista - talvez os mais violentos e, por causa disso, os únicos nomeados, pois somente a morbidez permite o ingresso de anônimos no obituário dos jornais. Assassinatos corriqueiros como o de Laverde, executado com o convencional método da bala, precisam de imagens fortes para virar notícia. A matéria sobre sua morte, longe de investigar quem foi e por que havia sido morto, busca apenas oferecer aos leitores a dose diária de morbidez pela qual anseiam. As fotos que acompanham o texto - uma grande poça de sangue e o quarto simples, de uma solidáo pungente - confirmam o tom melodramático que, segundo Monsiváis (2000), caracteriza a abordagem midiática da violência. O melodrama, diz o crítico, "se por um lado permite a assimilação de uma paisagem trágica, [...] por outro impede os cidadãos - convencidos dos poderes da fatalidade - de tomarem alguma atitude", já que o gênero "determinista por excelência, [...] põe-se a serviço da negação de saídas” (MONSIVÁIS, 2000: 231-233, tradução nossa).

Efeito parecido tem a morbidez, que "não apenas exorciza o crime situando-o como um evento remoto", como, "ao incorporá-lo ao espetáculo, banaliza o episódio sangrento" (MONSIVÁIS, 1999: 37, tradução nossa). Este elemento, antes mesmo da matéria sobre Laverde, aparece já na primeira página do romance - com o esquartejamento do hipopótamo - e retorna, cinco páginas depois, no boletim sobre Álvaro Gómez, quando uma câmera minuciosa enfoca o Mercedes-Benz metralhado, a janela destroçada, os restos de vidros espalhados por entre manchas de sangue seco (VÁSQUEZ, 2011: 18).

Evocadas em diferentes momentos, as recordaçôes traumáticas do narcoterrorismo se confundem com lembranças de transmissóes televisivas - como a execução de Luís Carlos Galán, alvejado em frente às câmeras quando fazia um comício no interior do país. Da caudalosa cobertura jornalística, porém, não emerge um conhecimento maior sobre as causas da violência e tampouco algum tipo de mobilização, mas sim o medo, a apatia, o desalento.

Chama atenção que, após o atentado, uma das primeiras providências de Yammara seja deixar de assistir aos telejornais. Mais tarde, quando o alheamento a que se entrega - "una vieja sitcom gringa, algo ligero y alegre y balsámico" (VÁSQUEZ, 2011: 92) - se mostra insuficiente para as sequelas que se multiplicam, também não é no noticiário que ele buscará uma saída. Ao receber um caderno do terapeuta com a recomendação de fazer um diá- 
rio - ou formular as perguntas que o afligem -, é a escrita que desponta para ele como horizonte de entendimento e superação do trauma. Dez anos seráo necessários para que seu relato se consubstancie em texto, mas o ponto de partida se dá na mesma noite, quando rabisca na folha em branco o signo que o norteará nos meses seguintes: um ponto de interrogação.

Seu primeiro gesto é voltar ao local do crime, onde se depara com a indiferença das coisas e a voracidade do esquecimento. Tudo segue como antes os engraxates, os vendedores de esmeralda -, sem vestígios do episódio que dilacerou sua vida. Sentado no café em frente à esquina do atentado, pergunta à garçonete se por acaso se lembra de Laverde ou do assassinato que ocorrera ali. A negativa o deixa perplexo. Teme que a morte do amigo, assim como a agonia, a febre e as alucinaçóes que ele próprio sofreu, tenham ocorrido sem deixar um único rastro no mundo, no passado e na memória da cidade. "Esto, por alguna razón, me perturbó. Creo que en ese momento decidí algo, o me sentí capaz de algo, aunque no recuerde las palabras que usé para formular la decisión" (VÁSQUEZ, 2011: 70).

A recusa ao esquecimento e a necessidade de compreensão, portanto, estão na base do seu relato. São elas que o impulsionam à casa de Laverde, no antigo bairro que, simbolicamente, aparece como o repositório do passado na cidade. "La Candelaria profunda es un lugar fuera del tiempo: en toda Bogotá, sólo en ciertas calles de esa zona es posible imaginar cómo era la vida hace un siglo" (VÁSQUEZ, 2011: 30). É também o desejo de esclarecimento que o faz aceitar o convite de Maya, viajando para La Dorada e mergulhando em cartas que em nenhum momento o mencionam, mas falam dele a cada linha (VÁSQUEZ, 2011: 138). As folhas de seu caderno continuam em branco, mas se insinuam como destino final de seus passos. "De repente estaba pensando en mi cuaderno virgen, en aquel signo de interrogación solitario y perdido, y unas palabras se esbozaron en mi mente: Quiero saber." (VÁSQUEZ, 2011: 125).

Dez anos depois, quando finalmente escrever suas memórias, Yammara não falará apenas das provaçôes que enfrentou, mas também dos outros envolvidos, a começar por Laverde, que morreu a seu lado impedido de contar sua história. Em uma cena do primeiro capítulo, encorajado pelo álcool, o ex-detento expressa - como "una tarea urgente [...], un deber inaplazable" (VÁSQUEZ, 2011:30) - o desejo de revelar seu passado, mas Yammara, incomodado com a intimidade que se forjava e com os riscos de permanecer em La Candelaria, prefere interromper a conversa. Mais tarde, seu relato restituirá a voz que negara ao amigo, fazendo dele, assim como outros personagens de Vásquez, a expressão de uma memória silenciada. Yammara percebe que não há como contar seu trauma sem evocar a biografia de Laverde, em cujas vicissitudes vê 
relaçôes inextricáveis com sua própria vida. Também precisa incluir a história de Maya, o infortúnio de Elaine, a queda do avião e as palavras dos pilotos antes de morrer. Tudo isso, conclui, faz parte de sua experiência. "La experiencia, eso que llamamos experiencia, no es el inventario de nuestros dolores, sino la simpatía aprendida hacia los dolores ajenos" (VÁSQUEZ, 2011: 85).

Não por acaso, o plural aparece no título do romance, que alude não a uma, mas a diversas coisas que caem: avióes, corpos, projetos familiares, além da própria cidade, que desmorona sob os ecos do poema de Aurelio Arturo (“y ardían desplomándose los muros de mi sueño.../ ¡Tal como se desploma gritando una ciudad!”). Conhecendo o passado de Laverde, Elaine e Maya, Yammara inscreve seu trauma em um contexto maior, interpretando-o não mais simplesmente como uma tragédia pessoal, mas como um dos incontáveis estilhaços de um desastre coletivo. Nesta paisagem de ruínas, fala em nome de sua geração, nascida quando o tráfico internacional de drogas dava os primeiros passos na Colômbia, no início dos anos 1970, e que cresceu encurralada pelo agigantamento dos cartéis, os sequestros em série, os assassinatos, os atentados a bomba e todos os outros crimes cometidos, em sua maioria, por Pablo Escobar, o mesmo que, em seus tempos de glória, despertou a fantasia das crianças com o prodigioso zoológico montado em sua fazenda perto de Medellín.

O propósito de fazer do livro um testemunho geracional é evidenciado no encontro entre Yammara e Maya, que começa no terceiro capítulo e se estende até o fim do romance. Impregnada de revelações, a conversa entre os dois transcorre na intimidade, "llenando con palabras el silencio de la noche cálida [...], como un cura y un pecador en el sacramento de la confesión" (VÁSQUEZ, 2011: 125). Esta atmosfera confessional, no recolhimento doméstico de uma cozinha, também caracteriza o encontro com Consu e se opóe à invasão estrepitosa dos jornalistas que publicam a matéria sobre Laverde. "Esa gente no respeta nada", diz a personagem (VÁSQUEZ, 2011: 75), para quem Yammara precisa provar que não é mais um repórter.

Fundamentais para as revelaçóes da trama, tais encontros aparecem como contraponto ao mundo ruidoso dos meios de comunicaçáo de massa; no lugar da apatia e da esterilidade, possibilitam o envolvimento e a compreensão. A memória, dizem os livros de Vásquez, é fundamental, mas não se pode buscar exclusivamente nas próprias lembranças. Lembra-se sempre junto - as recordaçôes de uns complementam-se com as dos outros. Yammara precisa de Maya para conhecer o passado de Laverde e, com isso, dar sentido à sua experiência. Maya, por sua vez, recorre a Yammara como uma peça única no quebra-cabeça que está montando (VÁSQUEZ, 2011: 124). Essa dependência impóe por vezes a ameaça de utilitarismo: 
[...] Maya volvió a recordar, volvió a dedicarse al fatigoso oficio de la memoria. ¿Fue para beneficio mío, Maya Fritts, o tal vez habías descubierto que podías usarme, que nadie más te permitía ese regreso al pasado, que nadie como yo iba a invitar esos recuerdos, a escucharlos con la disciplina y la dedicación con que los escuchaba yo. (VÁSQUEZ, 2011: 244)

Da mesma forma, a busca por informaçóes pode motivar expedientes ardilosos - como as mentiras de Yammara a Consu (VÁSQUEZ, 2011: 76) que suscitam, mais uma vez, questionamentos éticos. "No, ésos no eran mi muertos, yo no tenía derecho a escuchar esas palabras (así como no tengo derecho, probablemente, a reproducirlas en este relato, sin duda con algunas imprecisiones" (VÁSQUEZ, 2011: 84).

Unidos pelo medo e pela perda, Yammara e Maya enveredam pelo passado em busca das explicaçôes que a dor reclama e que o presente se nega a oferecer. Sua principal descoberta - assim como a dos protagonistas dos romances anteriores - é a dimensão histórica da violência, a inter-relação de suas vicissitudes com as grandes decisóes políticas. Por isso a influência dos 'grandes fatos' é explicitada tão amiúde. Como neste trecho: "Maya Laverde nació en la clínica Palermo de Bogotá en julio de 1971, más o menos al mismo tiempo que el presidente Nixon utilizaba por primera vez las palabras guerra contra las drogas en un discurso público" (VÁSQUEZ, 2011: 191, grifo do autor). Ou: "En 1973, poco antes de la creación de la Drug Enforcement Agency, Ricardo mandó a pirograbar, en un tablón, el nombre de la propiedad: Villa Elena” (VÁSQUEZ, 2011: 198).

Vásquez não faz "um estudo sociológico do narcotráfico", como bem disse Jorge Volpi (VOLPI, 2011), mas oferece outra narrativa - certamente mais complexa - a um fenômeno geralmente simplificado pelos meios de comunicação e interpretado, no mais das vezes, pela ótica hegemônica dos Estados Unidos. A presença dos Corpos de Paz no nascimento do narcotráfico na Colômbia é, para além de irônica, exemplo das violências que se escondem por trás de outras mais aparentes. Apesar da cartilha de boas intençóes, a instituição criada em 1961 pelo presidente Kennedy representou apenas um modo mais simpático e capcioso de intervir na América Latina, em meio a ações que vinham recrudescendo desde o início da Guerra Fria e envolveram, entre outras, a tentativa de invadir Cuba, os atentados a Fidel Castro e o apoio a ditaduras sanguinárias (RINKE, 2015).

Alguns desses paradoxos são flagrantes no romance: enquanto cidadãos norte-americanos continuam a chegar para os Corpos de Paz, os Estados Unidos cometem atrocidades diárias no Vietnã, intervêm na República Dominicana e se dilaceram em confrontos raciais (VÁSQUEZ, 2011: 141). Sob a fachada do assistencialismo, o astuto Mark Barbieri, em parceria com 
outros voluntários, instrui os camponeses no plantio de maconha e se torna, nas palavras de Laverde, muito mais do que um sócio, "un verdadero pionero" na produçấo da droga (VÁSQUEZ, 2011: 185). Mais tarde, o mesmo Barbieri ingressa no tráfico de cocaína e seduz Laverde com a promessa de lucros astronômicos. É ele, em suma, que alicia Laverde para o crime - o que, se não torna o colombiano uma vítima, ao menos distribui responsabilidades num tema que, ao concentrar-se nos países produtores (a "Guerra contra as drogas", o "Plano Colômbia"), costuma repartir desigualmente as parcelas de culpa.

Foi certamente por realçar essa complexidade - iluminando implicaçóes geralmente desprezadas - que, pouco depois de o livro ser lançado, o escritor argentino Rodrigo Fresán (FRESÁN, 2011) apontou Vásquez como um dos maiores romancistas políticos da literatura latino-americana contemporânea. Mesmo sem ser novidade, a participação de norte-americanos na gênese do tráfico na Colômbia corre o risco de cair no esquecimento, de táo pouco mencionada entre as informaçóes sobre a violência. Fora da Colômbia, onde o romance foi amplamente lido e divulgado, o desconhecimento é sem dúvida maior. O escritor peruano Santiago Roncagliolo, por exemplo, qualificou o episódio como uma "das revelaçôes mais inesperadas" feitas pela obra (RONCAGLIOLO, 2011).

Quando Vásquez escrevia o romance, aliás, o passado polêmico dos Corpos de Paz voltou a ficar em evidência na Colômbia, com o anúncio de que, após 29 anos de ausência, a instituição voltaria a atuar no país. Jornalistas como Poncho Rentería e o sociólogo Alfredo Molano criticaram o retorno, mencionando, entre outros fatores, a presença de voluntários do organismo no nascimento do tráfico de drogas. Em sua coluna no El espectador, Molano vinculou a volta dos Corpos de Paz ao acordo militar firmado meses antes por Estados Unidos e Colômbia, pelo qual os norte-americanos, com a justificativa de intensificar o combate à guerrilha e ao narcotráfico, passariam a utilizar sete bases estratégicas em território colombiano. "A associação é clara. Resta saber se essas duas políticas se complementam e se os gringuinhos acabarão fazendo a inteligência civil que os comandantes das bases requerem para suas operações", escreveu o sociólogo (MOLANO, 2009, tradução nossa).

Ainda em 2010, o acordo acabou sendo invalidado, e os voluntários dos Corpos de Paz retornaram à Colômbia independentemente disso, com a missão declarada de dar aula de inglês e colaborar em trabalhos comunitários. De todo modo, os comentários de Molano - semelhantes aos de muitos outros analistas - ilustram a atualidade e a voltagem política dos temas abordados por Vásquez. A guerra contra as drogas, fundamental para o destino dos personagens, há muito vem sendo condenada nos meios intelectuais mais pro- 
gressistas da Colômbia e da América Latina. "Os Estados Unidos disponibilizaram o mercado, os insumos e as duas condiçóes para fazer do cultivo de duas plantas inofensivas um negócio tâo próspero como o de armas: a proibição e a demanda", disse Molano em outro artigo (2014, tradução nossa).

Ao lançar este olhar crítico, investigando os antecedentes do narcotráfico, Vásquez buscou um caminho diferente em um tema não apenas saturado nos meios de comunicação, mas também abordado sobejamente pela própria literatura colombiana. De García Márquez a Tomás González, Laura Restrepo a Héctor Abad, Fernando Vallejo a Evelio Rosero, praticamente todos os grandes escritores do país tematizaram a violência em narrativas publicadas nas últimas três décadas. Parte importante delas remete ao ambiente de terror imposto por Pablo Escobar entre a primeira metade da década de 1980 e sua morte, em 1993, período em que a ameaça de extradição aos Estados Unidos levou o traficante e seus comparsas ("Los extraditables", como se intitularam) a pressionar o Estado com um conjunto de práticas brutais que incluiu o assassinato de figuras públicas (os chamados "magnicídios"), sequestros simultâneos (como os narrados por García Márquez em Noticia de un secuestro) e bombas em lugares de grande circulação, como supermercados, edifícios do governo, shopping centers e avióes. Em um artigo de 2001, María Elena Rueda apontava Rosario Tijeras como a última das obras pertencentes ao que denominou "Ciclo Pablo Escobar". Mas os anos seguintes mostraram que, tanto na literatura quanto, principalmente, na televisão e no cinema, o mundo do narcotráfico e, em particular, a figura ambígua de Escobar continuariam cada vez mais presentes.

Um dos exemplos é a série "Escobar, El patrón del mal", produzida pela rede colombiana Caracol TV, que apenas no primeiro capítulo, em 2012, registrou audiência de 11 milhóes de pessoas, batendo consecutivos recordes de público nos mais de 30 países em que foi exibida. Criada pelos filhos de duas vítimas famosas de Escobar, a série começa todos os capítulos com uma frase que sintetiza os princípios do "dever de memória": "Quien no conoce su historia está condenado a repetirla" - ou seja, é preciso lembrar para que não aconteça novamente. Porém, três anos depois, é inevitável se perguntar se as novas adaptaçóes da vida do traficante - representado agora por galâs como Benicio del Toro, Wagner Moura e Javier Bardem - não constituiriam um caso de "mercadorização" ou "saturação" da memória, para citar os fenômenos analisados, respectivamente, por Andrés Huyssen (HUYSSEN, 2000) e Régine Robin (ROBIN, 2003). Segundo levantamento da Caracol TV, mais de 30 livros já foram escritos sobre Pablo Escobar, assim como foram realizadas 14 produçôes audiovisuais, entre filmes de ficção, séries e documentários. A conta não inclui os recentes projetos hollywoodianos 
"Escobar: paraíso perdido" (2014) e "Narcos" (2015) - dirigidos pelo italiano Andrea di Stefano e pelo brasileiro José Padilha, ambos radicados nos Estados Unidos. Também náo considera a produção europeia "Escobar", em que o casal Javier Bardem e Penélope Cruz revive o romance de Escobar com a jornalista Virginia Vallejo. É de se esperar, com esse boom, que as agências de turismo de Medellín lucrem ainda mais com os pacotes que visitam lugares-chave da vida e da morte do traficante - o chamado "Pablo Escobar Tour" pode custar até 900 dólares.

Por esse motivo - o imenso acervo de informaçóes sobre o tema -, soa artificial o retrospecto que Maya e Yammara fazem dos anos do narcoterrorismo quase no fim do romance. Enfiadas em diálogos, são didáticas, e por isso ruins, as evocaçóes dos grandes lances da guerra dos "Extraditables" com o governo: o assassinato do ministro da Justiça Rodrigo Lara Bonilla; o assassinato do candidato à presidência Luis Carlos Galán; a bomba que derrubou um aviáo da Avianca - como se Vásquez assumisse aí um excessivo zelo por seu público não colombiano, preocupação também revelada no fato de o narrador referir-se à Colômbia como "mi país", como se o país do leitor fosse necessariamente outro. Além do didatismo (que aparece em outros diálogos dos dois personagens), o balanço histórico que fazem se apropria, praticamente sem retoque, de uma ideia já utilizada em Los informantes, a de "una vida regida por el lugar donde uno está cuando asesinan a otro" (VÁSQUEZ, 2004: 278). Naquele romance, o narrador comenta: "Mucho tiempo después, alguien me haría esa pregunta: ¿Dónde estaba cuando mataron a Escobar? Antes me habían preguntado: ¿Dónde estaba cuando mataron a Galán, a Pizarro?” (idem). Em El ruido de las cosas al caer, as mesmas perguntas são feitas por Yammara e Maya. “¿Dónde estaba usted cuando mataron a Lara Bonilla?”, começa ela (VÁSQUEZ, 2011: 227).

O trecho ganha força na sequência, quando os dois voltam à Fazenda Nápoles 17 anos depois de a visitarem pela primeira vez (na época crianças inocentes excitadas por conhecer o zoológico, e ainda por cima às escondidas). Ao chegarem à propriedade - antes suntuosa, agora derruída -, a decepçáo é inevitável. Náo tanto pela decadência do lugar, pelo abismo que o separa do esplendor de antes, mas pela sensaçáo de vácuo frente ao que a fazenda simbolizara para ambos (p. 234), o passado de perdas sintetizadas naquele antigo paraíso infantil (p. 236). No silêncio que guardam nesse instante, nas lembranças que surgem, e nos medos que voltam e abafam as sensaçôes anteriores, parece se condensar o propósito do romance. E, como contraponto, expressamente relegadas, as histórias sobre Pablo Escobar, sobre a ascensão e a queda do império mafioso, narradas como "una especie de película en cámara muy lenta” pelos meios de comunicação colombianos (VÁSQUEZ, 2011: 234). 
En cuanto al pasado de la propiedad, no nos interesó demasiado: las cosas que allí habían ocurrido, los negocios que se hicieron y las vidas que se extinguieron y las fiestas que se montaron y las violencias que desde allí se plantearon, todo eso formaba un segundo plano, un decorado. (VÁSQUEZ, 2011: 236)

\section{Referências bibliográficas}

ABAD FACIOLINCE, Héctor. “La música del ruido”, El Espectador, 6 maio 2011.

BARRIE, J. M. Peter Pan. Trad. Julia Romeu. Rio de Janeiro: Zahar, 2013.

BENJAMIN, Walter. "Sobre alguns temas de Baudelaire". In: A modernidade e os modernos. Rio de Janeiro: Tempo Brasileiro, 2000.

. "Sobre o conceito de história". In: . Magia e técnica, arte e política: ensaios sobre literatura e história da cultura. Trad. Sérgio Paulo Rouanet. São Paulo: Brasiliense, 1994. (Obras escolhidas, v. 1).

FRANCO, Jorge. Rosario Tijeras. Bogotá: Ministerio de Cultura, 1999.

FRESÁN, Rodrigo. "El sonido de un novelista al ascender”, Página 12, Buenos Aires, 12 jun. 2011. Disponível em: <http://goo.gl/qbpGpt>. Acesso em: 20 nov. 2015.

GUTIÉRREZ MAVESOY, Aleyda. Escritura y novela en Colombia, 1990-2005. 2014. Tese (Doutorado) - Faculdade de Filosofia, Letras e Ciências Humanas, Universidade de São Paulo. São Paulo, 2014.

HEYMANN, Luciana. O "devoir de mémoire" na França contemporânea: entre a memória, história, legislação e direitos. Rio de Janeiro: CPDOC, 2006. .

KLINGER, Diana. "Fernando Vallejo: a violência urbana e as ruínas da cidade letrada”. In: MORAES, Alexandre \& SCARDINO, Rafaela (Org.). Traços de um outro mapa: literatura contemporânea nas Américas. Vitória: Edufes, 2013.

MONSIVÁIS, Carlos. "Ciudadanía y violencia urbana: pesadillas al aire libre”. In: ROTKER, Susana (Org.). Ciudadanias del miedo. Caracas: Nueva Sociedad, 2000 .

. “De no ser por el pavor que tengo, jamás tomaría precauciones': notas sobre la violencia urbana”, Letras Libres, n. 34, maio 1999.

. El narcotráfico y sus legiones. In: - Viento rojo: diez historias del narco en México. Cidade do México: Plaza y Janés, 2004: 34-44.

MORETZSOHN, Sylvia. Jornalismo em tempo real: o fetiche da velocidade. Rio de Janeiro: Revan, 2002.

NIETZSCHE, Friedrich. Escritos sobre educação. Rio de Janeiro: Ediçóes Loyola, 2007. . Segunda consideração intempestiva: da utilidade e desvantagem da história para a vida. Rio de Janeiro: Relume Dumará, 2003.

NORA, Pierre (Ed.). Les lieux de mémoire. Paris: Gallimard, 1984.

. Realms of Memory: the construction of the French Past. New York: Columbia University Press, 1996. v. 1: Conflicts and Divisions.

. "O retorno do fato". In: LE GOFF, Jacques \& NORA, Pierre. História: novos problemas. Rio de Janeiro: Francisco Alves, 1995: 179-193. 
PIGLIA, Ricardo. Escenas de la novela argentina. Programa exibido na TV Pública argentina. Buenos Aires, 15 set. 2012. Disponível em: <https://www.youtube. com/watch?v=fpTjlSG4Pso >. Acesso em: 20 nov. 2015.

PLAZA, Caridad. "Diálogo de la lengua: Mano a mano entre el novelista peruano Santiago Roncagliolo y Juan Gabriel Vásquez, escritor colombiano, sobre el arte de narrar historias comprensibles y sobre la vida del escritor latinoamericano en España”, Quórum, Madrid, n. 16, 2006: 105-118.

RONCAGLIOLO, Santiago. "Lo que mata no son las drogas, lo que mata son los sicarios”, Tiempo, 14 jun. 2008.

ROTKER, Susana. Ciudadanias del miedo. Caracas: Nueva Sociedad, 2000.

RUEDA, María Elena. "La violencia desde la palabra”, Universitas Humanística, ano XXIX, jan./jun. 2001: 25-35.

VALLEJO, Fernando. La virgen de los sicarios. Bogotá: Alfaguara, 1994.

VÁSQUEZ, Juan Gabriel. El ruido de las cosas al caer. Madri: Alfaguara, 2011.

VOLPI, Jorge. "Iluminar la caída”. Portal Terra, México, 19 jun. 2011. Disponível em: <http://goo.gl/uLml82>. Acesso em: 20 nov. 2015.

WALDE, Erna von der. "La novela de sicarios y la violencia en Colombia", Revista Iberoamericana, v. I, n. 3, 2001: 27-40.

. "La sicaresca colombiana: narrar la violencia en América Latina”. Nueva sociedad, n. 170, nov./dez. 2000: 222-227.

Diogo de Hollanda Cavalcanti é doutor em Letras Neolatinas pela UFRJ, autor da tese "Deslocamento e memória na trilogia colombiana de Juan Gabriel Vásquez". Participa como convidado do GT/Anpoll "Relaçóes Literárias Interamericanas” e do grupo de pesquisa "Estudos literários interamericanos e transatlânticos", inscrito no diretório do CNPq. Organizou a reedição dos clássicos $O$ cemitério dos vivos, de Lima Barreto e Um passeio pela cidade do Rio de Janeiro, de Joaquim Manoel de Macedo (Planeta/Biblioteca Nacional, 2009), e traduziu diversos livros do espanhol, o mais recente foi o romance La cola de la serpiente, de Leonardo Padura (Benvirá, 2015). E-mail: diogodehollanda@yahoo.com.br 